\title{
¿TIENE SENTIDO QUE LAS UNIVERSIDADES PÚBLICAS DEJEN DE SER ADMINISTRACIONES PÚBLICAS EN LAS NUEVAS LEYES DEL SECTOR PÚBLICO Y DE PROCEDIMIENTO ADMINISTRATIVO COMÚN?
}

\author{
José Antonio Tardío Pato \\ Profesor Titular de Universidad, área de Derecho Administrativo. Universidad Miguel Hernández de Elche \\ joseatardio@gmail.com
}

\begin{abstract}
SUMARIO
I.- Introducción. II.- La naturaleza jurídica de las Universidades públicas en nuestros textos normativos, en la jurisprudencia tanto de nuestro Tribunal Constitucional como de nuestro Tribunal Supremo y en nuestra doctrina científica. III.- La consideración de las Universidades públicas en la legislación española sobre contratación del Sector Público, como reflejo de la concepción sustancial de "organismo de Derecho público” y “poder adjudicador” del Derecho de la Unión Europea. IV.- Especulaciones sobre la orientación de la exclusión del carácter de Administraciones públicas de las Universidades públicas en los Proyectos de Ley de "procedimiento administrativo común” y de "organización del sector público” de 2015 y nuestras conclusiones al respecto.
\end{abstract}

\section{I.- INTRODUCCIÓN}

A) El Proyecto de Ley de procedimiento administrativo común de las Administraciones públicas fechado en mayo de 2015, al indicar el ámbito de aplicación de dicha Ley, incluye a las Universidades públicas en el denominado sector público institucional (art. 2.2.c), junto a los que califica como "organismos públicos y entidades de Derecho público vinculados o dependientes de las Administraciones Públicas” (art. 2.2.a) y junto a las "entidades de Derecho privado vinculadas o dependientes de las Administraciones Públicas" (art. 2.2.b), precisando que las Universidades públicas se regirán por su normativa específica y supletoriamente por las previsiones de dicha Ley procedimental.

Si bien, después, al enumerar los entes que considera Administración pública (art. 2.4), engloba dentro de los mismos a los entes territoriales y a los "organismos públicos y entidades de Derecho público vinculados o dependientes de las Administraciones Públicas", pero excluye a las "entidades de Derecho privado vinculadas o dependientes de las Administraciones Públicas" y a las Universidades públicas.

En un apartado distinto, alude a las "Corporaciones de Derecho Público", diciendo que se regirán por su normativa específica, en el ejercicio de las funciones públicas que les hayan sido atribuidas por Ley o delegadas por una Administración Pública y, supletoriamente, por la citada Ley procedimental administrativa.

B) El Proyecto de Ley de Régimen Jurídico del Sector Público, también fechado en mayo de 2005, establece inicialmente el mismo esquema de entes integrantes del sector público institucional, en su art. 2.2: "organismos públicos y entidades de Derecho público vinculados o dependientes de las Administraciones Públicas" (art. 2.2.a); "entidades de Derecho privado vinculadas o dependientes de las Administraciones Públicas" (art. 2.2.b); y Universidades públicas (art. 2.2.c). Como también califica exclusivamente como Administraciones públicas a los entes territoriales y a los “organismos públicos y entidades de Derecho público vinculados o dependientes de las Administraciones Públicas” (art. 2.4), por lo que ya desde un principio excluye a las Universidades públicas del carácter de Administración pública.

Pero, más adelante, con referencia al sector público institucional estatal, amplía el elenco de entes integrantes del mismo (art. 84.1). Así, junto a los ya citados "organismos públicos y entidades de Derecho público vinculados o dependientes de las Administraciones Públicas" (dentro de los cuales incluye los organismos autónomos y las entidades públicas empresariales) y Universidades públicas (aquí las no transferidas), matiza, dentro de las “entidades de Derecho privado vinculadas o dependientes de las Administraciones Públicas", los casos de las 
sociedades mercantiles estatales y de las fundaciones del sector público (estatal). A los que añade, además, las "autoridades administrativas independientes"; los consorcios; y los fondos sin personalidad jurídica.

Las "autoridades administrativas independientes" estatales se definen como aquellas entidades de Derecho público que, vinculadas a la Administración General del Estado y con personalidad jurídica propia, tienen atribuidas funciones de regulación o supervisión de carácter externo sobre un determinado sector o actividad económica, por requerir su desempeño de independencia funcional o una especial autonomía respecto de la Administración General del Estado, lo que deberá determinarse en una norma con rango de Ley (art. 109.1). Por lo tanto, tal definición no permite englobar aquí a las Universidades públicas y, además, aparecen diferenciadas de éstas en la enumeración del art. 84.1. Y, al igual que las Universidades públicas, tampoco son consideradas Administraciones públicas, porque no aparecen mencionadas en el citado art. 2.4.

Si bien, parece producirse una contradicción al definirse los organismos públicos, que antes había diferenciado de las "autoridades administrativas independientes", pues el art. 88, donde se acomete tal definición, incluye ahora como supuesto de los mismos los organismos creados para la supervisión o regulación de sectores económicos, que, en la misma Ley, es lo característico de las citadas "autoridades administrativas independientes", según la definición que se da de las mismas en el art. 109.1.

En conclusión, debe resaltarse que se establece una diferenciación de las Universidades públicas no sólo respecto de los organismos autónomos y las entidades públicas empresariales (que siguen siendo entendidas como Administraciones públicas, en el art. 2.4), sino también de las "autoridades administrativas independientes".

Como también se separan de las sociedades mercantiles, las fundaciones del sector público, los consorcios y los fondos sin personalidad jurídica.

$\mathrm{Y}$, por otro lado, consigna el nuevo Proyecto de Ley que se regirán las Universidades públicas por la Ley 47/2003, General Presupuestaria, y por la nueva Ley del Sector Público, en lo no previsto en su normativa específica (art. 84.3).

Lo que no dejan claro los dos nuevos proyectos de Ley es por qué se incluye la novedad de dejar de considerarlas como Administraciones públicas y qué diferencia comporta para los entes públicos del sector institucional tener (como los organismos autónomos y las entidades públicas empresariales) o no (como las Universidades públicas y las "autoridades administrativas independientes") el carácter de Administración pública. No se cumple con la exigencia de fundamentación objetiva de las decisiones de los poderes públicos propia del Estado de Derecho y su consiguiente exteriorización a través de los instrumentos de motivación de tales decisiones.

\section{II.- LA NATURALEZA JURÍDICA DE LAS UNIVERSIDADES PÚBLICAS EN NUESTROS TEXTOS NORMATIVOS, EN LA JURISPRUDENCIA TANTO DE NUESTRO TRIBUNAL CONSTITUCIONAL COMO DE NUESTRO TRIBUNAL SUPREMO Y EN NUESTRA DOCTRINA CIENTÍFICA}

A) Para no remontarnos demasiado lejos, recordaremos primero, de forma sintética, su consideración jurídico-administrativa en la época del Régimen de Franco.

La Ley de 29 de julio de 1943, sobre Ordenación de la Universidad española, en su art. $1^{\circ}$, declara que la Universidad española "es una corporación de maestros y escolares" y, en su art. $8^{\circ}$, proclama que "tendrá plenitud de personalidad jurídica en todo lo que no esté limitado por la Ley y siempre dentro del ejercicio de sus funciones universitarias".

Y el Decreto de 9 de noviembre de 1.944 sobre régimen económico de las Universidades las sigue definiendo, en su art. $1^{\circ}$, como "corporaciones de maestros y escolares".

Pero, el Decreto de 14 de junio de 1.962, dictado en cumplimiento de las disposiciones transitorias $5^{\text {a }}$ y $6^{\text {a }}$ de la Ley de Entidades Estatales Autónomas, de 26 de diciembre de 1.958, para llevar a cabo la clasificación de entidades de este tipo y la regulación de subsistencia, modificación, fusión o supresión de las existentes, califica a las Universidades existentes como "Organismos Autónomos" del grupo B, que son aquéllos que atienden a los servicios que les están encomendados mediante subvenciones consignadas en los Presupuestos del Estado o mediante estas subvenciones y el rendimiento de los impuestos, arbitrios, tasas, recargos y exacciones que tengan establecidos (criterio marcado en la Disposición transitoria $5^{\text {a }}$ de la Ley de 1958).

En la Ley Villar Palasí de 1970, ya no se aplican a las Universidades calificativos relativos a su naturaleza jurídica. Tan sólo se indica que "las Universidades tendrán personalidad jurídica y patrimonio propio y gozarán de plena capacidad para realizar todo género de actos de gestión y disposición, sin más limitaciones que las establecidas por las Leyes" (art. 63.3). Su artículo 64.1 añade que "gozarán de autonomía” y su art. 66.1 que "cada Universidad se regirá por un 
Estatuto singular ajustado a las prescripciones de la presente Ley y que habrá de ser aprobado mediante Decreto a propuesta del Ministerio de Educación y Ciencia".

No obstante, en la mayoría de los Estatutos provisionales de las diversas Universidades de los años 1970 y 1971 , aprobados por sucesivos Decretos', dictados en virtud de la Disposición Transitoria Quinta de la Ley, se califica a la Universidad como "Organismo Autónomo" y como Organismo Autónomo3. Y un último grupo de Estatutos, simplemente, las adjetivan con el término genérico "Entidad de Derecho Público"4.

En cualquier caso, la Orden de 4 de julio de 1.972, de Presidencia del Gobierno, relativa a la elaboración de relaciones de funcionarios de Organismos Autónomos y la inscripción de los mismos en el Registro de Personal mantiene a las Universidades como Organismos Autónomos y les asigna una clave en la que se recogen las siglas del Ministerio de Educación y Ciencia, al que están adscritas.

Por lo que se refiere a la jurisprudencia, después de alguna Sentencia anecdótica que simplemente señala expresamente que "la Universidad es la Corporación que agrupa a todas las disciplinas de la Ciencia"5, las primeras sentencias relevantes se producen fuera del período, con la Constitución de 1978 aprobada, pero en relación con cuestiones planteadas antes de aprobarse la Ley Orgánica 11/1983, de Reforma Universitaria.

Se trata de Sentencias que cuestionan la legitimación de las Universidades para impugnar las decisiones de la Administración del Estado y que destacan que la solución se ha de buscar en el análisis de los preceptos reguladores de la naturaleza jurídico-administrativa del ente accionante. Su conclusión es que, "dado el régimen jurídico, organizativo y financiero (de las Universidades) que resulta de todo lo expuesto, se las ha de calificar, a los efectos de que se trata, de órgano de la Administración del Estado". A lo que añaden que "no es óbice el hecho de la reconocida personalidad jurídica de que disfrutan, ya que, de una parte, esa condición juega con plenitud de efectos sólo en sus relaciones externas o con terceros y, limitadamente, en cambio, frente a la Administración estatal, a la que están adscritas y, de otra, ello no implica necesariamente desvinculación e independencia absoluta del Estado, sino que, por el contrario, de las normas legales examinadas, resulta patente una vinculación y una dependencia de la Administración General, a la que aparecen sometidas a través del mecanismo jurídico de la tutela"6.

Pero, también se produjo una dirección jurisprudencial distinta a la anterior, en la que se enmarca la STS de 15 de febrero de 1982 (Sala $3^{\text {a }}$, RJ 1982/507) ${ }^{7}$ y la STS de 10 de febrero de 1983 (Sala 3 $3^{\text {a }}$, RJ 1983/6022) ${ }^{8}$, que, en suma, vienen a conceptuar a las Universidades como "Organismos Autónomos" de los previstos en la Ley de Entidades Estatales Autónomas de 1958, pero como "entes institucionales” con posiciones jurídicas propias frente al Estado.

En la doctrina científica, que también relataremos de modo muy sintético, destaca, en primer término, una primera dirección influida por la calificación de las Universidades como corporaciones que hizo la Ley de Ordenación

\footnotetext{
1 En una publicación del Boletín Oficial del Estado titulada “Estatutos provisionales de las Universidades” y realizada en 1972 (primera edición) y 1973 ( $2^{\text {a }}$ edición), se recogen todos ellos.

2 Así, los de la Universidad Autónoma de Barcelona, Granada, La Laguna, Murcia, Salamanca, Sevilla, Literaria de Valencia, Politécnica de Valencia, Valladolid y Zaragoza.

3 Estatutos de la Universidad de Barcelona, de Oviedo y de Bilbao.

4 Es el caso de los de la Universidad Politécnica de Barcelona, de los de la Universidad Complutense de Madrid, de los de la Universidad Autónoma de Madrid y de los de la Universidad de Santiago.

5 STS, Sala $3^{\text {a }}$, de 22 de marzo de 1973 (RJ 1983/1422, Considerando $3^{\circ}$ ) que no saca conclusiones de tal calificación para fundamentar su fallo.

6 SSTS de 20 de abril de 1982, Sala $3^{\mathrm{a}}$, RJ 1982/1990; 6 de octubre de 1983, Sala $3^{\mathrm{a}}$, RJ 1983/5029; 20 de enero de 1984, Sala $3^{\mathrm{a}}$, RJ 1984/185; y 25 de abril de 1985, Sala $3^{\mathrm{a}}$, RJ 1985/1955.
}

La STS de 9 de abril de 1985 (RJ 1985/1752) aunque mantiene la misma concepción, sin embargo, en contradicción con lo anterior, tampoco parece admitir dicha personalidad en las relaciones con terceros, pues desecha que la Universidad pudiese haber sido la demandada en el proceso, por considerar que "su personalidad jurídica y autonómica, no pueda llegar a superponerse ni a sobrellevar la carga procesal que sólo a la Administración compete”, de modo que sólo el Ministerio es el llamado a ser demandado.

7 Porque, a pesar de revocar la Sentencia de la Sala de lo Contencioso-Administrativo de la Audiencia Nacional, de 22 de diciembre de 1.979, en lo relativo al fondo del asunto, no entra ni siquiera a cuestionarse la admisión (basada en la personalidad del recurrente) de la demanda por la Sentencia apelada, en un supuesto de impugnación por la Universidad de Barcelona de una Orden del Ministerio de Educación y Ciencia (la de 1 de junio de 1.978, que establece la relación de plazas vacantes en el cuerpo de profesores adjuntos existentes en diversas Facultades).

8 Pues rechaza la solicitud de inadmisibilidad, propuesta por el Abogado del Estado, fundamentada en falta de legitimación de la Universidad para impugnar en vía contenciosa la Orden del Ministerio de Educación y Ciencia de 1 de junio de 1.978, como consecuencia de constituir aquélla un órgano integrado en la misma Administración estatal (Considerando $1^{\circ}$ del Tribunal Supremo). Se remite en este punto al Considerando $2^{\circ}$ de la

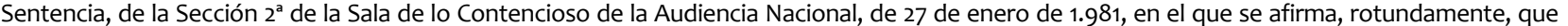
la Universidad no es un órgano del Ministerio, sino una Entidad Estatal Autónoma que goza de personalidad propia, incluso frente al Estado, y está legitimada para la interposición del recurso conforme al art. 28.1.b de la Ley de Jurisdicción de lo Contencioso y con su propia representación, cual dispone el art. 35.1 de ésta. 
Universitaria de 1943, que sigue directamente tal conceptualización o con matices; otra que resalta su consideración como entes institucionales del tipo de las entidades estatales autónomas de la época ${ }^{10}$; y otra que subraya que estamos ante entes públicos institucionales, con mecanismos de participación de la comunidad universitaria, los cuales constituyen más una especialidad dentro del género de los institucionales que un factor determinante de una nueva categoría"1.

9 L. JORDANA DE POZAS (1953, pág. 373 y ss.), con referencia a la Ley de Ordenación universitaria de 27 de julio de 1.943, decía que la concepción según la cual la Universidad es meramente un establecimiento público o un servicio de enseñanza superior a cargo de la Administración directa del Estado y prestado por funcionarios pertenecientes a cuerpos o escalafones encuadrados en un Ministerio, parecía totalmente abandonada. La Universidad es así —añade—, según el común consenso y el precepto legal (art. $1^{\circ}$ de la Ley de 27 de julio de 1943), una Corporación.

Y F. GARRIDO FALLA (1954, pág. 165 y ss.), sin embargo, subraya que la Universidad en la España de la época es uno de "los servicios públicos que se gestionan en forma corporativa".

"Servicio público es, porque atiende a una necesidad pública, porque es creada y costeada con los fondos públicos y porque es servida por personal que previamente ha adquirido la condición de funcionario público".

“Pero, al mismo tiempo, se ha elegido como más adecuada para su gestión la forma corporativa: las relaciones entre maestros y discípulos no es solamente la mera relación entre administradores y usuarios del servicio público; no se encuentra inconveniente en que ciertos cargos rectores se elijan o puedan elegirse a través de un sistema de elección y por miembros de la Corporación; finalmente, se concede cierta autonomía patrimonial y financiera" (Ob. cit., págs. 169 y 170).

En suma, considera, ahora, que la calificación de la Universidad como servicio público no nos lleva necesariamente al concepto de descentralización funcional o establecimiento público, es decir, a entes de tipo fundacional, sino que existen Corporaciones que "se originan, se conservan y se desarrollan por las mismas razones que el servicio público se crea y se mantiene, es decir, porque hay una necesidad pública que requiere atención y satisfacción directa por parte del Estado"; "pero que a su calidad de servicio público unen la peculiaridad de la forma corporativa en que se justifican" (Ob. cit., págs. 169 y 170).

10 F. GARRIDO FALLA que se había decantado anteriormente por naturaleza corporativa con matices, nos dice, en la primera edición de “Tratado de Derecho Administrativo", volumen I, de 1958 (pág. 305, en nota al pie, número 58), que es dudoso si la personalidad jurídica de la Universidad constituye un establecimiento público personificado (personificación del establecimiento concreto que sirve a la ejecución de un servicio público) o si se trata de una auténtica Corporación, como quiere el art. $1^{\circ}$ de la Ley de Ordenación universitaria de 29 de julio de 1.943 . Y, sin embargo, en el Volumen II de la misma obra, publicado en 1960 (págs. 350,en nota 17, 351, 352 y 353), pone ya a las Universidades como ejemplos de “Servicios públicos personificados", en su modalidad de "Establecimientos autónomos con personalidad jurídica propia, prestadores de servicios asistenciales”, que, en nuestro Derecho positivo del momento, caen dentro del ámbito de aplicación de la Ley sobre Régimen Jurídico de las Entidades Estatales Autónomas, de 26 de diciembre de 1958, y concretamente dentro de la categoría de los “organismos autónomos”.

A. GUAITA subraya, en su Derecho Administrativo Especial, en 1965 (también en el estudio de la voz "Instrucción Pública" en Nueva Enciclopedia Jurídica Seix, 1968, pág. 126 y ss. Nuestras citas son del primer trabajo), que los establecimientos docentes del Estado (incluidas las Universidades) “funcionan de iure y de facto como dependencias del Ministerio de Educación Nacional”. Este es quien nombra a los profesores que han de desempeñar los cargos de gobierno y dirección (a veces, a propuesta de los propios centros de enseñanza); quien aprueba y fiscaliza sus presupuestos; quien aprueba los planes de enseñanza; y quien nombra a todo el personal docente; por lo que todos ellos funcionan con un reducido régimen de autoadministración a efectos internos (Ob. cit., pág. 105). Aunque las Universidades y algunas Escuelas que después han pasado a ser universitarias están dotadas de personalidad jurídica, dicha personalidad "es muy débil, más legal que real” -dice GUAITA-, "Con todo, y en la escasa medida en que pueda hablarse en estos casos de personalidad jurídica, se trataría de fundaciones estatales, no de corporaciones: éstas están formadas por miembros personales con efectivas facultades de autogobierno: y en el caso de los centros docentes no hay propiamente miembros, sino funcionarios y beneficiarios de la enseñanza".

Por ello, a pesar de que el art. 1 de la Ley de Ordenación Universitaria llama a las Universidades Corporaciones de maestros y escolares, “está más en lo cierto el art. 10 cuando dice que las Universidades sólo pueden fundarse por Ley, pues en la actualidad las Universidades más son fundaciones estatales que Corporaciones" (1965, p. 106, nota 49).

Tras la regulación dada a las Universidades por la Ley General de Educación de 1970, G. ARIÑO ORTIZ, en su obra “La Administración Institucional..." (1972, $2^{\text {a }}$ ed. 1974. Nuestras citas las realizamos por la segunda edición), se refiere a las Universidades como ejemplo de entes en los que cabe perfectamente determinar los sectores de población interesados e instrumentar sobre los mismos una representación social, soporte de la autonomía. Pero añade que, siendo ello posible, sin embargo, no es así, en el momento en que se expresa, pues, en el mismo, estos entes «son meros instrumentos del Estado, perfectamente insertos e identificados con éste» (Ob. cit., pág. 135), “con una personalidad jurídica ficticia” (Ob. cit., pág. 82, nota 42), por lo que se decanta claramente por su naturaleza de “organismos autónomos” de la época.

Y E. LINDE PANIAGUA (1977, págs. 356-357 y 369) afirma que las Universidades son “Organismos Autónomos" de los definidos por la Ley de Entidades Estatales Autónomas de 26 de diciembre de 1.958 y considera que las relaciones entre la Administración del Estado y aquéllas deben calificarse de "relaciones de instrumentalidad", con toda la serie de connotaciones que esto lleva consigo. Entre dichas connotaciones, por un lado, destaca la "relación de dependencia" constante de las Universidades con el Ministerio de Educación y Ciencia, la cual se articula mediante directivas. $\mathrm{Y}$, por otro lado, resalta que dichos entes autónomos no tienen fines propios, sino que, por el contrario, la titularidad de los mismos es del ente matriz y su determinación no puede ni siquiera, radicarse en la Administración, sino que pertenece a la Comunidad.

11 Es el caso de la explicación de E. GARCIA DE ENTERRIA y TOMÁS-RAMÓN FERNÁNDEZ (1975, pág. 211). Estos autores ponen a las Universidades como ejemplo de relativización de la distinción entre Corporaciones e Instituciones, por la inserción de elementos organizatorios propios de uno de los tipos en el tipo contrario. Concretamente las incluyen como supuesto de entes institucionales inequívocos en los que se insertan representaciones sociales de interesados que, aún sin adquirir por ello la condición formal de miembros, colaboran en la gestión del ente y limitan correlativamente la libertad de mando instrumental del ente matriz sobre el mismo. "La falta de la condición de miembros de estas representaciones se acredita con sólo notar que el sostenimiento de los respectivos entes no es inmanente a los mismos, no es una carga que asumen los interesados, sino que recae sobre el ente fundador y también suelen carecer de un verdadero derecho activo a canalizar sobre ellos la acción del ente". Se trata, pues, de "fenómenos de colaboración de administrados en la Administración institucional o burocrática y no de autoadministración, por lo que no se trata de verdaderas corporaciones". 
B) Nuestra Constitución de 27 de diciembre de 1978 afecta cualitativamente al estatuto jurídico de las Universidades públicas. Pues reconoce, en su art. 27, párrafo 10, "la autonomía de las Universidades, en los términos que la Ley establezca”; proclama, en su art. 20.1.c., el reconocimiento y protección de la libertad de cátedra; y establece un sistema de autonomías territoriales, que determinan una nueva dimensión de la cuestión que venimos analizando.

Sin embargo, todavía el Real Decreto 1000/1979, de 27 de abril, por el que se aprueban las normas orgánicas provisionales del recién creado Ministerio de Universidades e Investigación, se refiere a las Universidades como “Entidades estatales autónomas adscritas al Ministerio de Universidades e Investigación” (art. 31), después de destacar, en su Preámbulo, el carácter provisional de la regulación establecida en el mismo, teniendo en cuenta "que la futura regulación de la autonomía universitaria hará obligado adaptar el funcionamiento del Departamento al contenido de dicha regulación".

La Ley Orgánica 11/1983, de Reforma Universitaria, prefiere no realizar concesiones terminológicas relativas a la naturaleza jurídica de las Universidades, indicando simplemente, en su art. 3.1, que "las Universidades están dotadas de personalidad jurídica y desarrollan sus funciones en régimen de autonomía y de coordinación entre todas ellas”.

Los primeros Estatutos de las Universidades de esta nueva época, previstos en la propia Ley Orgánica 11/1983 (art. 3.2, letra a, y art. 6, entre otros) como instrumento jurídico básico para el despliegue de la autonomía de éstas, que se fueron aprobando y publicando a partir de 1985, sí que intentaron ofrecernos calificaciones jurídicas de aquéllas, al igual que hicieran los Estatutos provisionales dictados al amparo de la Ley General de Educación de 1970.

Algunos optaron por definirlas simplemente como “entidades de Derecho Público que tienen personalidad jurídica y patrimonio propios" 12 , por lo que no hacían más que indicar que estábamos ante entes a los que el Ordenamiento les reconocía personalidad jurídica propia y que dicha personificación era de Derecho Público y no meramente de Derecho Privado, lo que se entendía como indicador de su consideración como Administraciones Públicas.

Pero el grupo más numeroso de ellos les atribuyó el carácter de Instituciones de Derecho Público que poseían personalidad jurídica y patrimonio propios ${ }^{13}$, lo que suponía dar un paso más, al indicar ya su conceptualización como "entes públicos institucionales", Administración Institucional en sentido estricto, y excluía, al menos en principio, la naturaleza corporativa.

Tan sólo los Estatutos de la Universidad de Sevilla, en su primera redacción ${ }^{14}$, calificaron a dicha Universidad como "Corporación de derecho público", rectificando en la segunda, en la que se pasaron a su caracterización como Instituciones de Derecho Público ${ }^{15}$.

Por otro lado, la Ley 4/1990, de Presupuestos Generales del Estado para 1991, al referirse al incremento de las retribuciones de los funcionarios públicos, distinguió ya el personal de las Universidades (art. 19.2.h.) del personal de la Administración del Estado y sus Organismos autónomos (letra a); de las Administraciones de las Comunidades

12 Art. 1 del Estatuto de la Universidad de Alicante, aprobado por Decreto 107/1985; art. 1 del Estatuto de la Universidad de Cádiz, Decreto 274/1985; art. 1 del de la de Córdoba, Decreto 184/1985; art. 1 del de la de León, tanto de su primera redacción (Real Decreto 1247/1985), como de la segunda (Real Decreto 876/1991); art. 1 de los Estatutos de la Universidad Complutense, tanto de su primera redacción (Real Decreto 861/1985), como de la segunda (Real Decreto 1555/1991); art. 1 del de la Universidad Politécnica de Madrid, Real Decreto 2536/1985; art. 1 del de la de Málaga, Decreto 173/1985; art. 3 del primer Estatuto de la Universidad de Salamanca, Real Decreto 1248/1985 (en el segundo, aprobado por R.D. 678/1988, de 1 de julio ya la califica como Institución de Derecho Público); y art. 1 del de la Universidad Politécnica de Valencia, Decreto 145/1985.

13 Art. 1 del Estatuto de la Universidad de Alcalá de Henares, Real Decreto 1280/1985; art. 1 del Estatuto de la Universidad de las Islas Baleares, tanto en su primera redacción (Real Decreto 1140/1985), como en la segunda (Real Decreto 1666/1989); art. 1 del de la Universidad Autónoma de Barcelona, Decreto 37/1985; art. 1 del de la Universidad de Barcelona, Decreto 217/1985; art. 1 de la Universidad Politécnica de Cataluña, Decreto 232/1985; art. 1 del de la de Cantabria, Real Decreto 1246/1985; art. 1 del de la Universidad de Extremadura, tanto en su primera redacción, aprobada por Real Decreto 1281/1985, como en su segunda redacción, aprobada por Real Decreto 1069/1991; art. 1 del de la de Granada, Decreto 162/1985; art. 1 del de la Universidad de La Laguna, Decreto 192/1985; art. 1 de la segunda redacción del Estatuto de la Universidad Autónoma de Madrid, Real Decreto 1085/1989, pues en la primera redacción redactada por el Gobierno, por haber transcurrido el plazo previsto para hacerlo la propia Universidad (Real Decreto 351/1986), se calificaba como Institución simplemente; art. 1 del de la Universidad de Murcia (Real Decreto 1282/1985), que la define como Institución dotada de personalidad jurídico-pública; art. 1 de las Normas estatutarias provisionales de la Universidad Pública de Navarra, redactadas y aprobadas por Decreto Foral 30/1989; art. 1 del de la Universidad de Oviedo, Real Decreto 1295/1985; art. 1 del de la Universidad del País Vasco, Decreto 7/1985; art. 1 del de la Universidad Politécnica de Las Palmas, Decreto 193/1985; art. 1 de la segunda redacción del Estatuto de la Universidad de Salamanca, Real Decreto 678/1988; art. 1 del de la de Santiago de Compostela (Decreto 204/1985); art. 2 del de la Universidad de Valencia (Estudio General), Decreto 172/1985; art. $2^{\circ}$ del de la Universidad de Valladolid, Real Decreto 1286/1985; art. 1 del de la Universidad de Zaragoza, Real Decreto 1271/1985; art. 1 del de la Universidad Nacional de Educación a Distancia, Real Decreto 1287/1985; el art. 1 de los Estatutos de la Universidad de Sevilla, Decreto 148/1988; art. 1 de las Normas estatutarias provisionales para la Universidad de La Coruña, Decreto 1/1990, así como el art. 1.1 de sus posteriores Estatutos, aprobados por Decreto 253/1992; y art. 1 de las Normas estatutarias provisionales dictadas para la Universidad de Vigo, Decreto 2/1990. Las Normas estatutarias provisionales dictadas por el Gobierno para la Universidad de CastillaLa Mancha (Real Decreto 1306/1987, arts. 1 y 2) y para la Universidad Autónoma de Madrid (Real Decreto 351/1986, derogadas después por los Estatutos autónomos de 1989, art. 1) dicen que dichas Universidades son simplemente una "institución dotada de personalidad jurídica y patrimonio propio, que actúa o se organiza en régimen de autonomía".

14 Art. 1 de su Estatuto, Decreto $163 / 1985$

15 Decreto $148 / 1988$ (art. 1). 
Autónomas y los Organismos de ellas dependientes (letra b); y de las Corporaciones Locales y Organismos de ellas dependientes.

Y el Real Decreto 1479/1988, por el que se establecieron normas para garantizar el mantenimiento de los servicios esenciales en la Administración del Estado incluyeron a las Universidades dependientes de la Administración del Estado, de forma diferenciada de los Organismos Autónomos de la misma ${ }^{16}$.

Años más tarde, la Ley Orgánica 6/2001, de Universidades, en su art. 2.1, reprodujo lo recogido en el art. 3.1 de la LRU ("las Universidades están dotadas de personalidad jurídica y desarrollan sus funciones en régimen de autonomía y de coordinación entre todas ellas"), añadiendo únicamente que "las Universidades privadas tendrán personalidad jurídica propia, adoptando alguna de las formas admitidas en Derecho".

Y las posteriores redacciones de los Estatutos de las Universidades se han pronunciado en similar sentido a las versiones anteriores, unos con la afirmación aséptica de configurarse como "entidades de Derecho público con personalidad jurídica y patrimonio propios" "ᄁ y otros con la calificación de la Universidad en concreto como "institución de Derecho Público con personalidad jurídica y patrimonio propio"”.

Fuera de los textos normativos, una primera interpretación influyente en esta época constitucional y de las Leyes Orgánicas citadas fue la recogida en los Dictámenes del Consejo de Estado sobre los Proyectos de Estatutos de diversas Universidades, en los que dirá que la Ley Orgánica 11/1983 "ha creado unas Universidades que, como entes administrativos autónomos, con autonomía directamente derivada del artículo 27.10 de la Constitución, no son asimilables a los Organismos Autónomos, que, como Entidades Estatales Autónomas, regula la Ley de 1958 y cuya autonomía es meramente instrumental y organizativa [...]"19.

En la jurisprudencia del Tribunal Supremo, la Sentencia de 10 de mayo de 1988 (Sala $5^{\text {a }}$, Ar. 4144) (2) $^{20}$ dirá que cada Universidad "constituye una Administración independiente, que hace de la nota de autonomía el eje de su régimen jurídico".

Y la STS, Contencioso, Sección 6a, de 1 de diciembre de 2003 (RJ 200319362, Ponente F. GONZÁLEZ NAVARRO, FJ $5^{\circ}$, letra C) destacó, por su parte, que, tanto a los efectos del art. 2.2 de la Ley 30/1992, como a los efectos del art. 1.2, letra d, de la Ley 29/1998, reguladora de la Jurisdicción Contencioso-Administrativa, son, sin perjuicio de su autonomía constitucionalmente reconocida, Entidades de Derecho público vinculadas a la Administración General del Estado o a la Administración de las Comunidades Autónomas, según los casos.

En la jurisprudencia constitucional, la STC 101/2003 (FJ $5^{\circ}$ ), resaltó "la peculiar naturaleza de las Universidades en el ámbito de las formas del Derecho de la organización administrativa, en el que aquéllas eran consideradas formalmente, por parte de la doctrina, como integrantes de la Administración institucional, conforme al modelo del establecimiento público, denominado frecuentemente en nuestro Derecho positivo como «organismo autónomo». En su estructura y organización, sin embargo, la Universidad se acerca más al modelo de las corporaciones pues se gobierna por la voluntad interna de sus miembros y se estructura conforme a modelos de representación democrática, en cuyo seno los vínculos de dependencia jerárquica de los profesores funcionarios, sin dejar de existir, son notoriamente más tenues que en el ámbito de otras formas organizativas de la Administración -arts. 27.10 CE; 2, 4 y 12 Ley Orgánica 11/1983, de 25 de agosto, de Reforma Universitaria-, vigente a la sazón, y hoy arts. 2, 6.2 y 3 Ley Orgánica 6/2001, de 21 de diciembre, de Universidades. Y, por eso, concluyó que, como indicaba el Ministerio Fiscal y en relación con el objeto del artículo (periodístico) que dio lugar a la resolución sancionadora [...], "la libertad de expresión del Catedrático aquí demandante ha de considerarse prácticamente idéntica a la de cualquier ciudadano".

16 Dice el citado art. 1: "Las situaciones de huelga que afectan al personal funcionario y laboral de la Administración del Estado y sus Organismos autónomos, Administración de la Seguridad Social y Universidades [...]”.

17 Así, p. ej. el art. 11. del vigente Estatuto de la Universidad Miguel Hernández de Elche, aprobado por Decreto 105/2012, del Consell de la Generalitat Valenciana, bajo la rúbrica "Naturaleza”, dice que es una "entidad de Derecho Público, dotada de personalidad jurídica y patrimonio propio, que goza de autonomía [... ]. Y, en términos semejantes, se pronuncia el art. 1.1 del vigente Estatuto de la Universidad de Alicante, aprobado por Decreto 25/2012, del Consell de la Generalitat Valenciana.

18 Así, p. ej., el art. 11. del Estatuto de la Universidad Complutense de Madrid, aprobado por Decreto 58/2003, del Consejo de Gobierno de la Comunidad de Madrid.

19 Así, el Dictamen n 47.784/JC, de 16 de mayo de 1985, relativo al Proyecto de Estatutos de la Universidad de Salamanca; el Dictamen $\mathrm{n}^{\circ}$ 47.686/JR, de 30 de abril de 1985, concerniente al proyecto de Estatutos de la Universidad de Alicante; el Dictamen $\mathrm{n}^{\circ} 47.937 / \mathrm{MA}$, atinente a la Universidad de Valladolid; y el Dictamen $n^{\circ}$ 48.015/FF, referente a la Universidad de Valencia.

20 En considerando que acepta de la Sala de lo ContenciosoAdministrativo de la Audiencia Territorial de Zaragoza de 14 de enero de 1988. 
$\mathrm{Y}$, en la doctrina científica de esta etapa, se han producido explicaciones que las han caracterizado como modalidad de Administración Institucional calificada como "organismos autónomos representativos" o como "entes públicos de naturaleza institucional de carácter especial" 22; como "Administración Independiente", ya sea como género distinto de la Administración Institucional23 ya sea como especie de la Administración Institucional diferenciada de los organismos autónomo $\mathrm{s}^{24}$; y como una nueva categoría mixta entre los entes públicos institucionales y las corporaciones públicas ${ }^{25}$. Pero, a su vez, se han categorizado como una manifestación de Entidades de Derecho público vinculadas a la Administración General del Estado o a la Administración de las Comunidades Autónomas (según los casos), de aquellas a que se refieren tanto el art. 2.2 de la Ley 30/1992, como el art. 1.2, letra d, de la Ley 29/1998, reguladora de la jurisdicción contencioso-administrativa, sin perjuicio de su autonomía constitucionalmente reconocida ${ }^{26}$.

$21 \quad$ F.J. JIMENEZ DE CISNEROS CID nos dice que la LRU ha establecido que el servicio público de la educación superior se preste por las Universidades, que se configuran, siguiendo el modelo tradicional, como Organismos Autónomos, dotados de personalidad jurídica y patrimonio propio, que funcionan en régimen de autonomía. Como tales organismos autónomos — prosigue-, están sujetos a la tutela del ente público territorial de que dependen (Estado o Comunidad Autónoma), que poseerá de este modo unas facultades de control e intervención en la vida y funcionamiento de la Universidad que habrán de ser respetuosas con el reconocimiento de la autonomía realizado por la Constitución y la propia Ley (1987, p. 419). Ahora bien, añade que, al responder a verdaderos fines e intereses de la sociedad y no sólo del Estado, aparecen revestidos de unas peculiaridades respecto del resto de los Organismos Autónomos que tienen reflejo en su organización y funcionamiento interno, así como en la relación que les une con el Estado. Y los denomina “Organismos Autónomos representativos”, porque sus órganos de gobierno son elegidos democráticamente por todos los sectores sobre los que va a recaer la acción del Organismo, que, de este modo, van a dirigir su actividad y funcionamiento (autogobierno) y porque además responden al principio de representación de los intereses que agrupan (comunidad universitaria), que, a veces, no tienen por qué coincidir con los intereses de la Administración que ostenta las facultades de tutela sobre su funcionamiento (Estado o Comunidad Autónoma) [1987, pp. 407-408]. Igualmente se pronunció, en su resumen de 1986 (págs. 585 a 593).

22 J.M. SOUVIRÓN MORENILLA, que destaca que su especialidad deriva de que están regidos por la LRU y su prelación de fuentes específicas (1988, p. 208).

23 A. CANO MATA las explica como Administraciones independientes, pero las estudia de forma diferenciada respecto de la denominada Administración Institucional (1987, 2145-2146).

24 E. GARCÍA DE ENTERRÍA y TOMÁSRAMÓN FERNÁNDEZ, ya en la $5^{\text {a }}$ edición del Tomo I de su "Curso de Derecho Administrativo", publicada en 1989, dejaron de incluir en determinados epígrafes a las Universidades como ejemplo de entes institucionales inequívocos en los que se insertan representaciones sociales de interesados, que no por ello adquieren la condición formal de miembros como manifestación de "fenómenos de colaboración de administrados en la Administración institucional o burocrática y no de autoadministración" (1989, p. 394), a diferencia de lo que hicieran en ediciones anteriores atrás citadas. Sin embargo, en otros epígrafes o apartados de dicha obra, han seguido refiriéndose a las Universidades como tipo de entes institucionales que se aproximan al tipo de los entes corporativos, por la relevancia de su ámbito de interesados y el reconocimiento parcial en favor de éstos de una facultad de participación en su gobierno; aunque dicha participación no llegue a convertirlos en verdaderos miembros activos en el sentido de una estructura corporativa genuina (1989, p. 414; 2004, p. 418; 2013, p. 455). Y, además, también las conceptualizan como "autoridades administrativas independientes", que, como otros entes enumerados en la Disposición Adicional $10^{\text {a }}$ de la Ley 6/1997, se caracterizan por "la limitación de los poderes del Gobierno y de la Administración respecto de ellos", "con estricto respeto a sus correspondientes ámbitos de autonomía, como excepción a la relación de instrumentalidad que aplica respecto de los demás organismos públicos" que dicha ley regula (2004, p. 435; 2013, ps. 471-472). También L. ORTEGA ALVAREZ, que destacó que, en el caso de las Universidades, era la propia norma constitucional la que aseguraba la posición de independencia. Sus autoridades desarrollan un servicio público ligado, al mismo tiempo, a la libertad de creación científica y, para ello, se les dota de una posición independiente del Ministerio de Educación y Ciencia en relación a determinadas actividades (1990, págs. 232-233).

25 En mi estudio sobre la configuración jurídico-administrativa de las Universidades públicas de 1994 (II, ps. 1266-1267), concluyo del siguiente modo:

"Desde la perspectiva de la distinción de personas jurídicas públicas en entes fundacionales o institucionales, por un lado, y entes corporativos, por otro, las Universidades públicas, que tienen en el art. 27.10 de la Constitución su garantía última de existencia y autonomía para salvaguardia de la libertad científica y su regulación básica en la Ley Orgánica de Reforma Universitaria de 1983, se nos aparecen con rasgos propios de los entes institucionales, pero también con algunos otros de los corporativos; por lo que consideramos, en último término, que, atendiendo a esa summa divissio, estamos ante una nueva categoría mixta respecto de las anteriores.

No en vano es ésta también la solución a la que hay que llegar actualmente en Alemania, cuya Ley marco federal de 1976 las califica como "Einrichtungen" (que podemos traducir, en último término como Instituciones) y simultáneamente como Corporaciones de Derecho Público (Körperschaften des öffentlichen Rechts). Y ésta es también la posible herencia histórica que tienen las Universidades españolas actuales, respecto de la posición jurídica de las medievales y de la Edad Moderna: nunca fueron exclusivamente corporaciones, sino fundamentalmente fundaciones reales, concejiles o de nobles y prelados, con derechos corporativos; como también lo fueron las Universidades alemanas de finales del Siglo XVIII (y también, quizá, el resto de las europeas continentales) tal y como manifiesta, con fórmula afortunada, el Derecho General de los Estados Prusianos de 1.794 (ALR), al calificar a las Universidades, en aquel momento, como "Veranstaltungen" estatales (que también podríamos traducir como Instituciones estatales) con derechos corporativos. $Y$, efectivamente, podemos asumir también que dichos entes jurídico-administrativos de naturaleza mixta son, a su vez, Administraciones independientes, por contar con un status autónomo frente a la acción (y, por ello, frente a la responsabilidad) del Gobierno.

Así pues, al no poder reconducirlas ya a los "Organismos autónomos administrativos", ni a los otros grupos de entes más generales señalados, nos impide aplicar regímenes jurídicos en bloque a las Universidades y es necesario acudir a un estudio analítico y pormenorizado de la normativa vigente en materia universitaria e intentar integrar las lagunas acudiendo a los instrumentos aportados por la teoría de aplicación e interpretación de las normas jurídicas (eso sí, en un marco de distribución de competencias entre el Estado y las Comunidades Autónomas, sin perjuicio de los que corresponden a las Universidades en ejercicio de su autonomía) [...]".

26 J. GONZÁLEZ PÉREZ y F. GONZÁLEZ NAVARRO (2004, pp. 276-277), que se había recogido también en la STS, Contencioso, Sección 6ª, de 1 de diciembre de 2003 (RJ 2003l9362, FJ $5^{\circ}$, letra C), de la que fue ponente F. GONZÁLEZ NAVARRO y que hemos citado supra. 


\section{III.- LA CONSIDERACIÓN DE LAS UNIVERSIDADES PÚBLICAS EN LA LEGISLACIÓN ESPAÑOLA SOBRE CONTRATACIÓN DEL SECTOR PÚBLICO, COMO REFLEJO DE LA CONCEPCIÓN SUSTANCIAL DE “ORGANISMO DE DERECHO PÚBLICO” Y “PODER ADJUDICADOR” DEL DERECHO DE LA UNIÓN EUROPEA}

A) En el art. 1.9 de la Directiva Europea 2004/18/CEE, son considerados "poderes adjudicadores", a los efectos de la misma, el Estado, los entes territoriales, los organismos de Derecho público y las asociaciones constituidas por uno o más de dichos entes o de dichos organismos de Derecho público.

$Y$, a su vez, es calificado de "organismo de Derecho público" cualquier organismo: a) creado específicamente para satisfacer necesidades de interés general que no tengan carácter industrial o mercantil; b) dotado de personalidad jurídica; y c) cuya actividad esté mayoritariamente financiada por el Estado, los entes territoriales u otros organismos de Derecho público, o bien cuya gestión se halle sometida a un control por parte de estos últimos, o bien cuyo órgano de administración, de dirección o de vigilancia esté compuesto por miembros de los cuales más de la mitad sean nombrados por el Estado, los entes territoriales u otros organismos de Derecho público.

Lo que se completa diciendo que, en el anexo III de la Directiva, "figuran las listas no exhaustivas de los organismos y de las categorías de organismos de Derecho público que cumplen los criterios enumerados en las letras a), b) y c) del párrafo segundo", añadiendo que los Estados miembros notificarán periódicamente a la Comisión las modificaciones que se hayan producido en sus listas.

Pues bien, en los listados del Anexo III, aparecen incluidas las Universidades públicas en Estados de sistema jurídico-administrativo más semejante al nuestro. Así, para Francia, con el simple término de "Universités", dentro de la categoría de los establecimientos públicos nacionales; para Italia, con el sintagma "Università statali", junto a otros entes relacionados con las Universidades; y para Alemania, dentro de la categoría de "Colectividades", con la expresión "Wissenschaftliche Hochschulen". Pero incluso, en el Reino Unido, de sistema jurídico-administrativo más diferente del nuestro, se recoge la categoría "Universities and Colleges financed for the most part by other contracting authorities".

Y, para España, en apartado de difícil inteligencia, se incluyen en el listado del Anexo III los organismos y entidades de derecho público sujetos a la "Ley de Contratos de las Administraciones Públicas", salvo los que forman parte de la Administración General del Estado, forman parte de la Administración de las Comunidades Autónomas o forman parte de las Corporaciones Locales, y las entidades gestoras y los servicios comunes de la Seguridad Social.

En cualquier caso, desde el punto de vista subjetivo, basta que una de las partes sea poder adjudicador para que el contrato sea público, de modo que entonces sólo faltará que concurran los requisitos de onerosidad, celebración por escrito y que su objeto coincida con el previsto en la Directiva (art. 1.2, letra b).

En el Real Decreto Legislativo 2/2000, que aprobó el Texto Refundido de la Ley de Contratos de las Administraciones públicas y que estaba vigente en el momento de la aprobación de la citada Directiva Comunitaria, estaban sometidos a dicha Ley en España, las tres Administraciones territoriales y los organismos autónomos en todo caso y las restantes entidades de derecho público con personalidad jurídica propia, vinculadas o dependientes de cualquiera de las Administraciones públicas, siempre que en aquéllas se diesen los siguientes requisitos: a) que hubiesen sido creadas para satisfacer específicamente necesidades de interés general que no tuviesen carácter industrial o mercantil y b) que se tratase de entidades cuya actividad estuviese mayoritariamente financiada por las Administraciones públicas u otras entidades de derecho público, o bien, cuya gestión se hallase sometida a un control por parte de estas últimas, o cuyos órganos de administración, de dirección o de vigilancia estuviesen compuestos por miembros más de la mitad de los cuales sean nombrados por las Administraciones públicas y otras entidades de derecho público. Lo que se matizaba, finalmente, añadiendo que lo anterior, sin perjuicio de lo establecido en la disposición final primera, que precisaba qué preceptos tienen el carácter o no de legislación estatal básica.

La fórmula básica de calificación de las demás entidades sometidas a la tal Ley distintas de las tres Administraciones territoriales era pues la misma del art. 2.2, tanto de la Ley 30/1992, como de la Ley 29/1998, sin perjuicio de los criterios adicionales de las letras a y b citadas.

B) Con ese marco normativo europeo, la Ley 30/2007 y el vigente Real Decreto Legislativo 3/2011, por el que se aprueba el Texto Refundido de la Ley de Contratos del sector público no sólo han incluido a las Universidades dentro la figura más amplia denominada "poder adjudicador", sino también dentro la categoría más restringida englobada en esta última, calificada como "Administraciones públicas". 
¿Qué diferencia existe entre ser mero poder adjudicador y ser además de lo anterior Administración pública o no? Pues que dicha legislación sea tan sólo aplicable plenamente o parcialmente. E incluso estar dentro o no de la categoría de Administración pública o no tiene repercusiones sobre la jurisdicción aplicable y el carácter público o privado de los contratos.

Si el sujeto es una Administración pública a los efectos de la Ley, su régimen será el propio de los contratos administrativos típicos recogido en dicha legislación o el de los contratos administrativos especiales, en su caso (art. 19, puntos 1 y 2 ).

Pero, si el sujeto es Poder Adjudicador que no sea Administración Pública a los efectos de la Ley (p. ej. Fundaciones del Sector Público), entonces estamos ante contratos privados, según el art. 20.1 del Real Decreto Legislativo 3/2011, y se aplicará, en cuanto a su régimen jurídico, el criterio de los actos separables recogido en el art. 20.2.

Así, en cuanto a la preparación y la adjudicación, se sigue el mismo orden de prelación que para los contratos administrativos especiales ( $1^{\circ}$, normas específicas; $2^{\circ}$, el Real Decreto Legislativo y sus normas de desarrollo; $3^{\circ}$, restantes normas de Derecho Administrativo; y $4^{\circ}$, normas de Derecho Privado) y, entre tales normas específicas, destacan las incluidas en el art. 190 relativas a la adjudicación de los contratos (que son las generales del Real Decreto Legislativo con reducción de algunas exigencias: no se requiere la intervención del comité de expertos para valorar el carácter anormal o desproporcionado de las ofertas; no se exige su publicación en los Diarios oficiales nacionales, sino tan sólo en el de la Unión Europea, etc.).

Pero, en lo atinente a los efectos y extinción, rige el Derecho Privado. Aunque, según el $2^{\circ}$ párrafo del art. 20.2, también se les aplicarán los arts. 105 a 108 sobre la modificación de los contratos, que rigen igualmente para los demás contratos privados. Y, asimismo, les resultan aplicables otras normas del Real Decreto Legislativo, como la que establece que el lugar de contratación será el de la sede del órgano de contratación, salvo que, en su clausulado se establezca otra cosa (art. 27.2) o que se perfeccionarán de acuerdo con su legislación específica (art. 27.1). Y J.A. MORENO MOLINA indica, a su vez ${ }^{27}$, que también se les aplica las normas del Libro I del Real Decreto Legislativo 3/2011 (arts. 22 a 108, donde se regulan no sólo la modificación de los contratos, sino, igualmente, el régimen de invalidez de los mismos; la capacidad y solvencia del empresario contratista; y el objeto, precio y cuantía del contrato).

Por lo que se refiere a la jurisdicción aplicable, si el sujeto es una Administración pública a los efectos de la Ley, su jurisdicción será la propia de los contratos administrativos, o sea la contencioso-administrativa. Pero, si el sujeto es un Poder Adjudicador que no sea Administración pública a los efectos de dicha Ley (caso de las Fundaciones del Sector Público), rige el criterio de los actos separables y se distingue (art. 21.2, inciso final) entre preparación y adjudicación, por un lado, que corresponde a la jurisdicción contencioso-administrativa y efectos, cumplimiento y extinción, por otro, que pertenece a la jurisdicción civil.

C) La nueva Directiva 2014/24/UE no parece conllevar cambios sustanciales respecto a lo anterior en el marco normativo comunitario, pues se acoge una definición de "poder adjudicador" y de "organismo de Derecho público" idéntico al de la Directiva 2004/18/CEE y se mantiene el mismo concepto de contratos públicos, bastando, desde el punto de vista subjetivo, que una de las partes sea poder adjudicador, de manera que sólo se requerirá, además, que concurran los requisitos de onerosidad, celebración por escrito y que su objeto coincida con el previsto en la Directiva (art. 2.1.5).

Únicamente destaca, como innovación, la distinción dentro de los “poderes adjudicadores" entre "autoridades, órganos y organismos estatales" (los que figuran en el Anexo I y las entidades que los sucedan) y "poderes adjudicadores subcentrales" (todos aquellos que no sean estatales, con clara referencia a los de carácter regional o de carácter local), sin que después se incluyan consecuencias de tal diferenciación.

D) Y es que, en el Derecho de la Unión Europea, desde el punto de vista subjetivo, lo que prima no es la calificación jurídica que cada Estado otorgue a sus entidades, sino criterios sustanciales como la financiación de la entidad en cuestión por el Estado, sus entidades regionales o locales, o la influencia dominante de estos poderes territoriales sobre ellas.

Han sido éstos los criterios que han venido siendo utilizados para la configuración del concepto de empresa pública en las Directivas 80/723/CEE y 85/413/CEE.

Y son los criterios empleados por las Directivas contractuales citadas para la definición de "organismo de Derecho público", o para la aplicación de tales Directivas a entidades que no tengan la consideración de poder adjudicador pero estemos ante contratos subvencionados por éstos (en más de un $50 \%$ y en los ámbitos

27 J.A. MORENO MOLINA y F. PLEITE GUADAMILLAS (2012, p. 159). 
objetivos acotados por dichas Directivas ${ }^{28}$ ). Como también se han usado por la jurisprudencia del TJUE relativa al procedimiento de aplicación propio de los contratos del sector público (véanse las SSTJUE de 15 de mayo de 2003 , C-214/00, Comisión/España, y 16 de octubre de 2003, C-283/00, Comisión/España).

Por eso, igualmente, en relación con la aplicación de las Directivas comunitarias de contratación pública a una Universidad de base privada como es la Universidad británica de Cambridge, la STJUE de 3 de octubre de 2000 (asunto C-380/98) ha declarado que la expresión «financiada por una o varias entidades adjudicadoras» que figuraba en las Directivas comunitarias 92/50/CEE, 93/36/CEE y 93/37/CEE debe interpretarse en el sentido de que en ella se incluyen las becas o subvenciones concedidas por una o varias entidades adjudicadoras para fomentar la labor investigadora, así como las becas para estudiantes que las autoridades locales competentes en materia de educación abonan a las Universidades para cubrir los gastos académicos de determinados estudiantes (no así las sumas abonadas por una o varias entidades adjudicadoras, bien en el marco de un contrato de prestación de servicios que comprenda trabajos de investigación, bien como contrapartida por la prestación de otros servicios, tales como asesoramiento u organización de conferencias).

Y, por ello, después de destacar que el término «mayoritariamente» debe interpretarse en el sentido de que significa "más de la mitad" y que, para valorar correctamente el porcentaje de financiación pública de un organismo determinado, es preciso tener en cuenta todos los ingresos que dicho organismo obtenga, incluidos los que resulten de una actividad mercantil, culmina afirmando que un organismo como la Universidad de Cambridge puede ser calificado como "entidad adjudicadora" y estar sometido por ello a las exigencias de dichas Directivas.

Si bien, dicha calificación debe efectuarse sobre una base anual y el período que debe considerarse más adecuado para calcular el modo de financiación de dicho organismo es el ejercicio presupuestario en el que se inicia el procedimiento de adjudicación de un contrato determinado, debiendo entenderse que dicho cálculo ha de efectuarse tomando como base las cifras disponibles al inicio del ejercicio presupuestario, aunque tengan el carácter de previsiones ${ }^{29}$.

Es por tal jurisprudencia, pues, que, en el Anexo III de la Directiva 2004/18/CEE, se incluyese para el Reino Unido como "organismo de Derecho Público" la categoría de "Universities and Colleges financed for the most part by other contracting authorities".

\section{IV.- ESPECULACIONES SOBRE LA ORIENTACIÓN DE LA EXCLUSIÓN DEL CARÁCTER DE ADMINISTRACIONES PÚBLICAS DE LAS UNIVERSIDADES PÚBLICAS EN LOS PROYECTOS DE LEY DE “PROCEDIMIENTO ADMINISTRATIVO COMÚN" Y DE “ORGANIZACIÓN DEL SECTOR PÚBLICO” DE 2015 Y NUESTRAS CONCLUSIONES AL RESPECTO}

Como no se explica en la Exposición de Motivos de los nuevos proyectos de Ley por qué son excluidas las Universidades públicas de la calificación como Administraciones públicas, es difícil aventurar cuál es el propósito de los redactores de los correspondientes anteproyectos y del Consejo de Ministros al convertirlos en proyectos de Ley.

El mismo hecho de no reflejarse en la motivación de tales textos normativos ya constituye un signo de arbitrariedad prohibido por el art. 9.3 CE por ausencia de la exteriorización de la fundamentación objetiva de las correlativas decisiones del poder público ${ }^{30}$.

Pero, a su vez, el ejemplo de la legislación contractual pública española, al establecer un distinto régimen jurídico y una diferente jurisdicción aplicable, según el ente tenga o no la consideración de Administración pública a dichos efectos, nos indica que la citada exclusión de las Universidades puede generar más perturbaciones interpretativas que ventajas, con el consiguiente desconcierto para los operadores jurídicos y, casi siempre, perjuicios para la ciudadanía.

Si lo que se pretende es destacar que las Universidades ostentan un régimen jurídico peculiar diferenciado del propio de los organismos autónomos y de las entidades públicas empresariales y del correspondiente a las Administraciones públicas territoriales, para eso no hace falta que se dejen de calificar como Administraciones públicas, pues ya la Ley 6/1997 (en el caso de las Universidades públicas no transferidas a las Comunidades Autónomas)

28 Art. 8 de la Directiva 2004/18/CEE. Y art. 13 de la Directiva 2014/24/UE.

29 Así se recoge en el fallo de dicha Sentencia.

30 E. GARCÍA DE ENTERRÍA y TOMÁS-RAMÓN FERNÁNDEZ subrayan que el Estado de Derecho supone la exigencia imperativa e inexcusable del fundamento adicional de la razón para toda decisión en la que el poder se exprese (2013, p. 524). Se contrapone así el Estado de Derecho al denominado “decisionismo" (SCHMITT, 1934, p. 12), para el cual la decisión del poder público se justifica en sí misma, en la mera voluntad (1934, p. 27), sin necesidad de tal fundamento objetivo (SCHMITT, 1922, págs. 61-62). Y de arbitrariedad, por carecer de fundamento objetivo, habla la STS 18/12/2007 (RJ 2007/9082, en FJ. 2º párrafo 7) y la STS 24/9/2008, RJ 2008/4570, FJ 2, párrafo 3). 
consignaba la aplicación preferente de sus normas especiales y tan sólo la aplicación supletoria de dicha Ley, sin despojarlas por ello de su veste de Administración pública.

Y tampoco comportaba problemas su consideración como "entidad de Derecho público con personalidad jurídica propia vinculada a las Administraciones territoriales", a los efectos de la aplicación preferente de determinadas normas, como las relativas a los órganos colegiados, que se desprendía, además, del mismo texto de la Ley 30/1992, por la remisión en varios apartados del mismo a las normas privativas de las distintas Administraciones públicas y por su consideración por la jurisprudencia constitucional como preceptos no básicos.

Pero, no tiene ningún sentido que puedan llegar a ser excluidas las Universidades públicas de la aplicación de normas de la Ley reguladora del procedimiento administrativo común del art. 149.1.18 CE. Pues, según el contenido acotado por la jurisprudencia constitucional, en dicha Ley se recogen los principios y normas (normas-regla, apostillaríamos nosotros-) que prescriben la forma de elaboración de los actos; los requisitos de validez y eficacia de los mismos; los modos de su revisión; los medios de su ejecución; y la garantía general de los particulares en el seno del procedimiento (STC 50/1999) y esto debe ser uniforme en todo el Estado para todas las entidades de Derecho público.

Por otro lado y a título de ejemplo, la propia legislación orgánica de las Universidades, después de definir el patrimonio de las Universidades públicas (art. 80.1 de la Ley Orgánica 6/2001), reconoce a éstas la titularidad de bienes de dominio público (art. 80.2), que no se establece abiertamente para los organismos públicos de la Administración General del Estado, en la Ley 6/1997 o en la Ley 33/2003; lo que es un indicador claro de que las Universidades públicas son entes públicos que deben contar con potestades administrativas propias de las Administraciones públicas territoriales.

En estos momentos, no se discute que las Universidades públicas ostenten las prerrogativas o potestades atribuidas por la Ley 33/2003 para la protección de los bienes públicos (recuperación de oficio de bienes públicos y demás de su art. 41), sin necesidad de que se reconozcan expresamente dichas potestades a los entes universitarios. El art. 41.1 de la Ley 33/2003 dice que tales potestades las tendrán las Administraciones públicas para la defensa de su patrimonio y la consideración actual de las Universidades públicas como Administraciones públicas a los efectos del art. 2.2 de la Ley 30/1992 y del art. 1.2, letra d, de la Ley 29/1998 facilita dicho entendimiento. ¿Pero qué ocurrirá si se mantiene su pérdida de consideración como Administraciones públicas? Tendría que ser resuelto por vía interpretativa, lo que generaría, a buen seguro, distintas direcciones y la consiguiente inseguridad jurídica.

\section{BIBLIOGRAFÍA}

ARIÑO ORTIZ, G. (1974) “La Administración Institucional (Bases de su régimen jurídico). Mito y realidad de las personas jurídicas del Estado", Instituto de Estudios Administrativos, Madrid, $1^{\mathrm{a}}$ ed. 1972, $2^{\mathrm{a}}$ ed. 1974.

GARCÍA DE ENTERRÍA, E. y FERNÁNDEZ RODRÍGUEZ TOMÁS-RAMÓN,

- (1975) “Curso de Derecho Administrativo”. Tomo I. Ed. Civitas. Madrid. $2^{\mathrm{a}}$ edición.

- (1989) "Curso de Derecho Administrativo". Tomo I. Ed. Civitas. Madrid. $5^{a}$ edición.

- (2004) "Curso de Derecho Administrativo". Tomo I. Ed. Thomson-Civitas. Pamplona. 12 edición.

- (2013) “Curso de Derecho Administrativo". Tomo I. Ed. Thomson-Civitas. Pamplona. 16ª edición. GARRIDO FALLA, F.,

- (1954) “Intervencionismo estatal y Educación Nacional”. Revista de Educación n² 26. Servicio de Publicaciones del Ministerio de Educación Nacional, pag. 165 y ss.

- (1958) “Tratado de Derecho Administrativo”. Volumen I, 1ª edición, Instituto de Estudios Políticos. Madrid.

- (1960) “Tratado de Derecho Administrativo". Volumen II, $1^{a}$ edición, Instituto de Estudios Políticos. Madrid.

GONZÁLEZ PÉREZ, J. y GONZÁLEZ NAVARRO, F., (2004) “Comentarios a la Ley de Régimen jurídico de las Administraciones públicas y del Procedimiento Administrativo Común”. Tomo I, $3^{\mathrm{a}}$ edición, Thomson-Civitas. Madrid.

GUAITA, AURELIO,

- (1965) “Derecho Administrativo Especial”, Tomo II. Zaragoza

- (1968) “Instrucción Pública” en Nueva Enciclopedia Jurídica Seix. Tomo XIII, pag. 126 y ss. 


\section{JIMENEZ DE CISNEROS CID, F.J.,}

- (1986) Voz "Organismos Autónomos", $2^{\mathrm{a}}$ parte, en Tomo XVIII de la "Nueva Enciclopedia Jurídica Seix". Editorial Francisco Seix, S.A. Barcelona, pags. 585 a 593.

- (1987) “Los Organismos autónomos en el Derecho Público español: Tipología y régimen jurídico”. Instituto Nacional de Administración Pública. Alcalá de Henares-Madrid.

JORDANA DE POZAS, L., (1953) "La autonomía universitaria". Ponencia presentada en la Asamblea de las Universidades españolas que se reunió en Madrid y Alcalá, del 11 al 16 de julio de 1.953. Está publicada en "Estudios de Administración Local y General" de dicho autor. Instituto de Estudios de Administración Local. Madrid 1961, pág. 373 y ss.

LINDE PANIAGUA, E., (1977) “La autonomía universitaria”. RAP nº 84.

MORENO MOLINA, JOSÉ ANTONIO; PLEITE GUADAMILLAS, FRANCISCO, (2012) Texto Refundido de la ley de Contratos del Sector Público. Ed. La Ley.

ORTEGA ALVAREZ, LUIS, (1990) “Manual de Derecho Administrativo", de L. PAREJO ALFONSO, A. JIMENEZ BLANCO Y L. ORTEGA ALVAREZ. Ed. Ariel S.A., Barcelona, ps. 227 y ss.

\section{SCHMITT, CARL,}

- (1922) Politische Teologie. Vier Kapitel zur Lehre von der Souveranität ("Teología Política. Cuatro capítulos sobre la teoría de la soberanía"). Citamos por su traducción española de Javier Conde, incluida en el libro "Estudios Políticos". Carl Schmitt. Editorial Doncel. Madrid 1975.

- (1934) Über die drei Arten des wissenschaftlichen Denkens ("Sobre los tres modos de pensar en el pensamiento jurídico"). Citamos por su traducción española de Monserrat Herrero publicada por la Editorial Tecnos SA. Madrid 1996.

SOUVIRÓN MORENILLA, J. M. (1988) "La Universidad española. Claves de su definición y régimen jurídico institucional”. Secretariado de Publicaciones de la Universidad de Valladolid.

TARDÍO PATO, JOSÉ ANTONIO, (1994) “El Derecho de las Universidades públicas españolas”. Editorial PPU SA, Barcelona, Volumen II, págs. 1266 y 1267. 